\title{
Influence of Excess Power Utilization in Power-to-Heat Units on an Integrated Energy System with $100 \%$ Renewables
}

\author{
Carsten Bode Gerhard Schmitz \\ Institute of Engineering Thermodynamics, Hamburg University of Technology, Denickestr. 17, 21073 Hamburg, \\ Germany, \{c.bode, schmitz\}@tuhh.de
}

\begin{abstract}
This paper presents the effect which the utilization of excess power in Power-to-Heat units has on an energy system which is fully supplied by renewables. For this, a possible future German integrated energy system consisting of the power, heat and gas sectors is modeled using the TransiEnt Library in Modelica ${ }^{\circledR}$. The first system contains electric energy storage units, Power-to-Gas as well as Gas-to-Power plants and hot water storage units as energy storage technologies. The heat supply does not use excess power, and an option to curtail renewable power generation is added. The system costs are optimized by using simplified models in MATLAB ${ }^{\circledR}$ and designed in Modelica afterwards to include the dynamic effects. In a second system, excess power can also be used in existing electric heat pumps and in a third system as well in existing electric heating rods installed in the hot water storage tanks instead of curtailing renewable energy generation. This reduces the component sizes and thus the cost of the system because only control has to be added to enable this behavior.

Keywords: Integrated Energy System, 100\% Renewables, Power-to-Heat, Energy System Analysis
\end{abstract}

\section{Introduction}

To reduce the effects of climate change, the United Nations have created the Paris Agreement (United Nations, 2015). This is a big challenge because $\mathrm{CO}_{2}$ emissions have to be decreased to a minimum which can only be achieved by massive integration of renewable energies in all energy sectors. Because the most promising renewable energies produce electricity directly, e.g. photovoltaics or wind turbines (International Energy Agency, 2016), and to use good storage capacities in the other sectors, sector coupling will become inevitable.

Many studies have been conducted in recent years, examining how future integrated energy systems may be designed, e.g. Benndorf et al. (2014); Gerhardt et al. (2015); Henning and Palzer (2015); Nitsch et al. (2012); Pape et al. (2014); Teske et al. (2015). In most cases, those studies are conducted with simplified models. Most commonly, quasi-stationary models are optimized over a whole year in time steps of one hour using Mixed Integer Linear Programming (MILP) to find the most cost-efficient configu- ration of an energy system. Those models neglect dynamic effects, e.g. time constants of storage units or rapid changes which occur faster than the time resolution of the models.

Therefore, the search for a cost-efficient configuration of a future integrated energy system consisting of the power, heat and gas sectors was conducted using simplified quasi-stationary models first and then detailed, dynamic models for the exact system design in Bode and Schmitz (2018). This work has been extended by adding more detail to enable the examination of the influence which the utilization of excess power in Power-to-Heat $(\mathrm{PtH})$ units has on the overall system.

One option to implement dynamic models is the programming language Modelica (Modelica Association, 2018) which enables equation-based and object-oriented model development. Due to this approach, physical equations can be written directly in the code and good reusability as well as simple maintenance are guaranteed.

\section{Previous Work}

In Bode and Schmitz (2018), renewable energy production and end use energy demand curves are generated for the future energy system of Germany including the power, heat and gas sectors for a year when those sectors will be fully supplied by renewables. End use of heat includes low temperature heat whereas the end use of gas contains high temperature heat and non-energetic use of gas. Generation and consumption are matched using different electric energy storage technologies (lithium-ion battery, pumped hydro storage or adiabatic compressed air energy storage), Power-to-Gas units (electrolyzer and methanation unit), gas storage volumes, Gas-to-Power units (gas turbine or combined cycle gas turbine), heat producers (solar thermal collector, electric heat pump, gas heat pump, gas boiler) and hot water storage units; see Table 1 and Figure 1. Energy transmission is assumed to be ideal.

The different storage and conversion technologies are charged and discharged in a given order, e.g. PHS, LIB, PtG, CCGT. So in the case of negative residual load, if the PHS unit is fully charged or is already operating at maximum power, the LIB will be charged and so on.

This integrated energy system is implemented in two different ways: First, as a dynamic model, using detailed, dynamic models from the open-source TransiEnt 


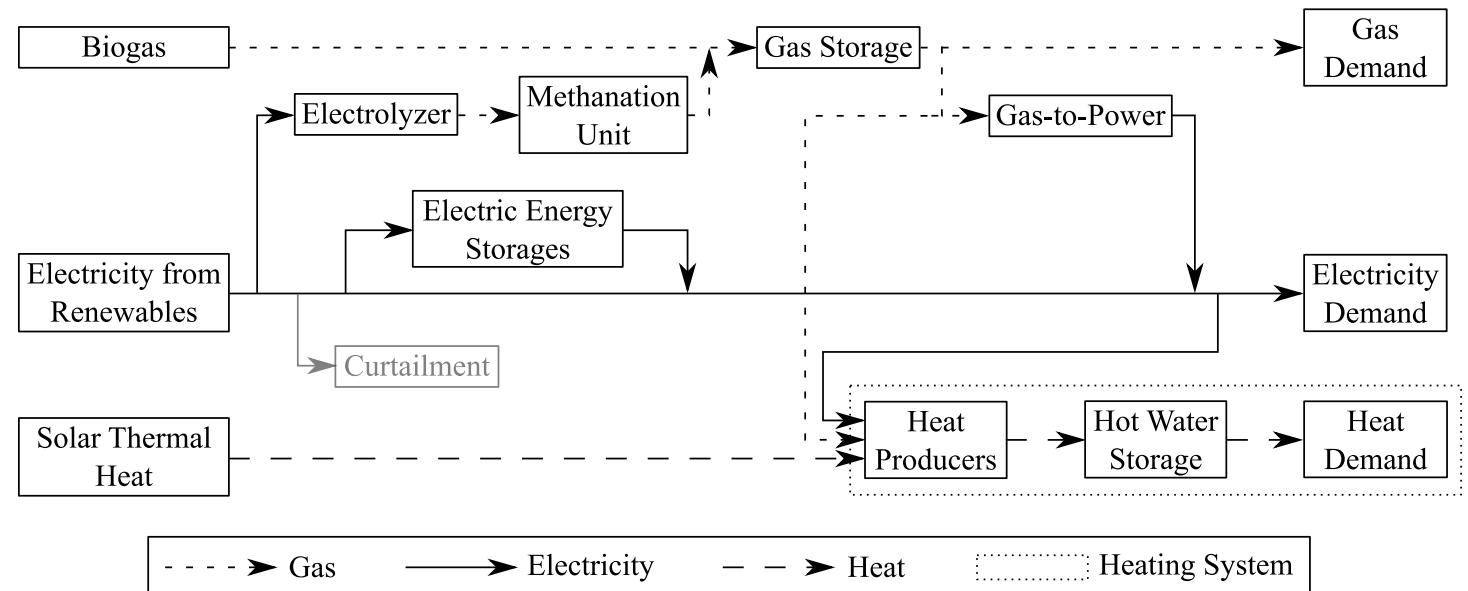

Figure 1. Overall system with energy flows between all components examined by Bode and Schmitz (2018). Curtailment (in grey) is added in this work.

Table 1. Abbreviations of components in the system

\begin{tabular}{ll}
\hline Component & Abbreviation \\
\hline $\begin{array}{l}\text { Lithium-ion battery } \\
\text { Pumped hydro storage }\end{array}$ & LIB \\
$\begin{array}{l}\text { Adiabatic compressed air } \\
\text { energy storage }\end{array}$ & PHS \\
Power-to-Gas unit (electrolyzer & A-CAES \\
and methanation unit) & PtG \\
Gas-to-Power unit & GtP \\
Gas turbine & GT \\
Combined cycle gas turbine & CCGT \\
\hline
\end{tabular}

Library (Hamburg University of Technology, 2018; Andresen et al., 2015) and models under development, which are implemented in Modelica in the simulation environment Dymola (Dassault Systèmes, 2018). Second, as a simplified model using quasi-stationary equations in MATLAB (MathWorks, 2018a) to guarantee low computing times to be able to compare a lot of system configurations in regard to cost. However, due to the high level of detail, the heating system is included in this system using gas or electricity demand curves taken from detailed Modelica simulations.

To find the best system configuration, first, the heating system is simulated to create the electricity and gas demand curves for the heat supply. Second, the simplified models are used to simulate a wide variety of combinations of the storage and conversion technologies with different sizes. It is ensured that all storage units have the same state of charge (SOC) at the beginning and at the end of the year and that all demands are met. Third, the most promising configurations are again designed in Modelica and at last compared regarding the cost.

\section{Approach}

First, a cost-efficient system configuration has to be found. This is achieved by applying the optimization algorithm patternsearch from the MATLAB Optimization Toolbox (MathWorks, 2018b) on the simplified MATLAB model of Bode and Schmitz (2018) with 15 min time steps to which the ability to curtail renewable energy generation is added. In the former configuration of the system, all produced renewable electric energy has to be consumed by the consumers or storage units as not to waste energy. With this strategy, the PtG capacity is designed for the peak load which occurs only once per year. Adding curtailment leads to higher operation hours of the plants and thus to lower specific cost.

The heat, which is not generated by solar thermal collectors, is supplied by an electric heat pump in combination with an electric boiler and an electric heating rod installed in the hot water storage. Gas heat pumps and gas boilers were excluded because they were not cost-efficient and the potential of excess power utilization is the highest in the electrically driven heat producers. The heating system is implemented in the MATLAB model by using electricity demand curves from the heating system modeled in Modelica.

Different combinations of storage technologies and charging orders are tested based on the results of Bode and Schmitz (2018) and optimization runs are started from several starting points to find different local minima. In a multi-dimensional numerical optimization one can never be sure if the found minimum is the global minimum or just a local one. So, the best minimum found is used and assumed to be the global minimum. As Henning and Palzer (2015) state, there are a lot of different solutions with only slightly differing cost. Also, the results are highly dependent on a lot of assumptions, especially prices in the far future, so the used result here is just a possible, but likely solution.

Second, this solution is designed by simulating the de- 
tailed Modelica system model (System 1, S1) over a whole year. The renewable, PtG and GtP nominal power are changed iteratively to ensure the same SOC of all storage units at the end as at the beginning of the year while keeping the electric energy storage sizes and maximum curtailment power constant.

Third, excess power utilization in PtH units is implemented in the detailed models in Modelica. So, energy, which would otherwise be curtailed, i.e. wasted, is used directly in electric heat pumps (S2) or additionally in electric heating rods in the hot water storage tanks (S3). This way, heat generation is shifted to times with a lot of renewable generation. These systems are designed as well using the Modelica system models under the same conditions as S1 but keeping the maximum of the sum of curtailed power and used excess power in the heating system constant.

All simulations are conducted with the Dymola solver Radau IIa and a tolerance of $10^{-6}$.

\section{Models}

The existing models of Bode and Schmitz (2018), i.e. quasi-stationary MATLAB and dynamic Modelica models, are extended by adding curtailment. In the Modelica models, the heating system is also modeled in more detail to enable a better quantification of the use of excess power in the PtH units.

\subsection{Curtailment}

Instead of actually reducing the power production of renewables in case of an overproduction, this excess power is consumed by a curtailment model. This way, it can be included in the existing storage technology structure in the models. The curtailment model has a maximum power, an infinite power gradient and an infinite energy capacity.

\subsection{Heating System}

The considered heating system, which is modeled in Modelica, is shown in Figure 2. With this model, a power consumption curve is created which is used by the simplified MATLAB model as well as S1 as a demand curve. In S2 and S3, the heating system model is included in the overall system model to enable direct coupling; see Figure 1 .

\subsubsection{Solar Collector}

In the formerly used solar collector model, the water, which absorbs the solar radiation, is modeled using the TILMedia Library (TLK-Thermo GmbH and Institut für Thermodynamik, Technische Universität Braunschweig, 2018). In reality, usually a water-glycol mixture is used to avoid freezing but due to the unavailability of open-source media data for this medium in the TILMedia Library, pure water is used. At low ambient temperatures, low water temperatures are reached, which leads to freezing, and thus to warnings from the used media data. The freezing
Table 2. Positions of the inlets, outlets and the electric heating rod in the hot water storage, measured from the bottom (Recknagel et al., 2017)

\begin{tabular}{llr}
\hline Component & & Height in $\mathrm{m}$ \\
\hline Electric heat pump & inlet & 1.7 \\
& oulet & 1.2 \\
Solar collector & inlet & 0.8 \\
& oulet & 0.3 \\
Electric heating rod & & 1.0 \\
Space heating & inlet & 1.0 \\
& oulet & 1.8 \\
Hot water and process heat & inlet & 0.0 \\
& oulet & 2.0 \\
\hline
\end{tabular}

does not influence the model results, because at those times, the solar radiation is so low that no heat is produced, but the simulation is slowed down due to the output of those warnings. Therefore, a simple water model is implemented, using constant density $\rho=989.9 \mathrm{~kg} / \mathrm{m}^{2}$ and specific heat capacity $c_{\mathrm{W}}=4184 \mathrm{~J} /(\mathrm{kg} \mathrm{K})$ based on the fluid model TILMedia_SplineWater between $10^{\circ} \mathrm{C}$ and $75^{\circ} \mathrm{C}$ at 1 bar. The specific enthalpy $h$ is calculated using the caloric state equation with the temperature $T$ and reference point 0 at $T_{0}=273.15 \mathrm{~K}$ with $h_{0}=59.65 \mathrm{~J} / \mathrm{kg}$.

$$
h=c_{\mathrm{W}}\left(T-T_{0}\right)+h_{0}
$$

\subsubsection{Hot Water Storage}

To model the hot water storage in a more realistic way, the existing model is extended, making it possible to add more ports in different heights. This way, for instance, the solar collector can feed the hot water into the lower part of the storage while the electric heat pump charges the upper part; see Figure 2. The heights used from Recknagel et al. (2017) are given in Table 2.

An electric heating rod is also added to the storage which works like the existing electric boiler model. Because of this, the electric heat pump does not have to be designed for the maximum heating capacity which only occurs once in a few years. Due to much lower specific cost of the electric heating rod, which is assumed to be the same as for the electric boiler $\left(70 € / \mathrm{kW}_{\text {th }}\right.$ (Elsner et al., 2015)), the cost of the whole system can be reduced.

\subsubsection{Consumer Side}

To simplify the control structure and speed up the simulations, the consumer models are simplified.

First, the consumers model is combined with the pump model. The necessary mass flow rate is calculated using the specific enthalpy calculated by the TILMedia fluid model at the outlet using the desired temperature, the specific enthalpy at the inlet and the consumed heat flow rate. With this model, the controller for the pump can be left out. Additionally, the back-mixing valve with its controller can be omitted as long as it is ensured that the temperature in the 


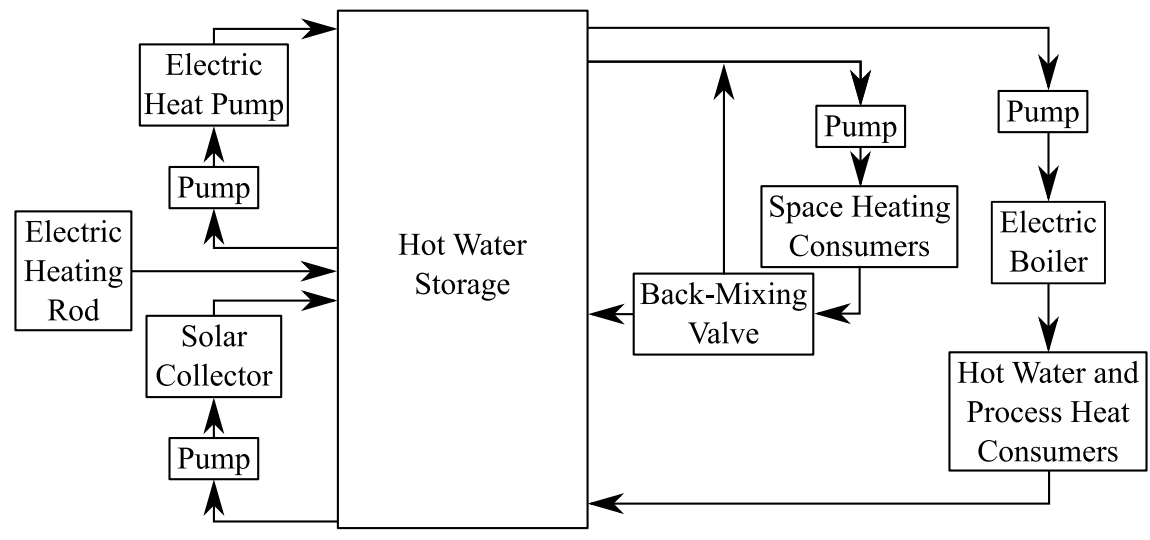

Figure 2. Considered heating system with modeled water flows.

corresponding control volume of the hot water storage is always above the current supply temperature defined by the heating curve. This is guaranteed by the control of the heat producer.

Second, on the process heat and hot water consumer's side, the electric boiler can be added to the combined pump-consumer model using the same principle as described above with a desired electric boiler outlet temperature of $60^{\circ} \mathrm{C}$. The temperature after the consumer is assumed to be $10^{\circ} \mathrm{C}$.

All these simplifications have been validated against the more detailed models to ensure correct behavior.

\subsubsection{Electric Heat Pump}

The electric heat pump model is also combined with the pump model as it is done for the consumers but more equations have to be added to ensure useful behavior. If the specific enthalpy at the inlet overshoots the desired specific enthalpy at the outlet, the mass flow is set to zero and the specific enthalpy is just passed through to the outlet. This way, the electric heat pump does not overheat. In addition, the mass flow rate can be limited to avoid high peaks.

For this model, a validation against the detailed models has been conducted as well.

\subsubsection{Heating System Control}

Proportional $(\mathrm{P})$ controllers are favored over PI or PID controllers in general for control due to higher simulation speed and negligible control errors. The model LimPID from the ClaRa library (Hamburg University of Technology et al., 2018; Brunnemann et al., 2012) is modified and used, leaving out the smooth activation feature because it was found to be unsuitable in some cases.

The control of the pump for the solar collector is changed to make it more realistic to work in matched-flow operation. Volume flows between 8 and $401 /\left(\mathrm{m}^{2} \mathrm{~h}\right)$ with temperatures between $75^{\circ} \mathrm{C}$ and $90^{\circ} \mathrm{C}$ are used (Späte and Ladener, 2011). To implement this behavior, a $\mathrm{P}$ controller is used. To avoid chattering, a hysteresis is implemented, which turns the pump on if the inlet temperature is $5 \mathrm{~K}$ above the temperature in the solar collector and turns it off again if the temperature difference is below $2 \mathrm{~K}$. Minimum on and off times of $1 \mathrm{~h}$ each are also added to limit the switching events.

The control of the electric heat pump is modified to enable the use of excess power. The existing $\mathrm{P}$ controller, which is responsible for the normal operation of the heat pump, has a set value of $0.5 \mathrm{~K}$ above the maximum supply temperature for space heating of $45^{\circ} \mathrm{C}$ (the minimum supply temperature is $35^{\circ} \mathrm{C}$ ) and measures the top temperature of the storage. For the excess power utilization, a second $\mathrm{P}$ controller is added with the same set value as the first controller but the measured value is the temperature of the fifth out of ten control volumes (counted from the top). The output is limited to the available excess power and added to the output of the first controller and again limited by the nominal power of the heat pump.

To control the electric heating rod in the hot water storage in normal operation, i.e. without the use of excess power, a controller is turned on when the ambient temperature is below the bivalence point or if the temperature at the top of the storage is $0.5 \mathrm{~K}$ below the desired value. Its set and measured values are the same as for the heat pump controller.

If excess power should be used in the electric heating rod in the hot water storage as well, a second controller is added here, similar to the heat pump controller. The set temperature is $75^{\circ} \mathrm{C}$ to increase the storage capacity. The output is limited by the remaining excess power, added to the output of the first controller and limited to the maximum power of the heating rod.

The required electric base load for the heat supply is calculated by the sum of the outputs of the first controller of the electric heat pump and the electric heating rod, respectively. The additional power used is the used excess power.

To avoid a direct influence of the base load on the excess power which is fed to all the storage technologies, a first order block is set after the heating system. The use of excess power directly decreases the base load which would instantly increase the excess power. This would 
Table 3. Mathematical and numerical properties of the different systems.

\begin{tabular}{lrrr}
\hline & S1 & S2 & S3 \\
\hline No. of equations & 2645 & 4294 & 4395 \\
No. of nontrivial equations & 1946 & 3253 & 3348 \\
No. of differentiated variables & 73 & 86 & 86 \\
$\begin{array}{l}\text { No. of time states } \\
\text { Biggest nonlinear system of }\end{array}$ & 49 & 62 & 62 \\
equations before manipulation & 10 & 23 & 27 \\
$\begin{array}{l}\text { Biggest nonlinear system of } \\
\text { equations after manipulation }\end{array}$ & 1 & 3 & 3 \\
No. of event iterations & 6015 & 20550 & 23809 \\
CPU time in h & 0.47 & 1.72 & 12.44 \\
\hline
\end{tabular}

influence all storage technologies and slow down the simulation. A small time constant of $60 \mathrm{~s}$ is sufficient and does not distort the results.

\subsubsection{Design of Components}

The electric heat pump and electric heating rod in the hot water storage tank were sized for a bivalent operation (Recknagel et al., 2017). This means that the electric heat pump should be able to supply all the heat at the bivalence point which was chosen to be $-5^{\circ} \mathrm{C}$ according to Recknagel et al. (2017). The standard ambient temperature was calculated using a weighted average of the standard ambient temperatures from DIN EN 12831 (DIN Deutsches Institut für Normung e.V., 2008) of the six biggest German metropolitan regions according to IKM (2018) which results in $-12.40^{\circ} \mathrm{C}$. Using the standard load profile approach from BDEW et al. (2016), daily mean values of the heat demand at standard ambient temperature and at the bivalence temperature are calculated. With an assumed efficiency of the hot water storage of $99 \%$, the electric heat pump and the electric heating rod should have nominal heat flow rates of $137.6 \mathrm{GW}_{\text {th }}$ and $31.04 \mathrm{GW}_{\text {th }}$ respectively. The maximum mass flow of the pump for the electric heat pump is assumed to be $3 \cdot 10^{6} \mathrm{~kg} / \mathrm{s}$.

The electric boiler, which increases the temperature of the water for the hot water and process heat demand, is designed so that the highest occurring heat flow rate in that year can be supplied.

The area of the solar collector is chosen to produce the desired heat according to Bode and Schmitz (2018) and the volume of the hot water storage is calculated using a specific value of $0.075 \mathrm{~m}^{3} / \mathrm{m}^{2}$ (Recknagel et al., 2017).

\subsection{Mathematical and Numerical Properties}

The different systems vary strongly in their mathematical and numerical properties as is shown in Table 3. The CPU times were measured on a 64 bit cluster with Intel ${ }^{\circledR}$ Xeon ${ }^{\circledR}$ E5-2650 v3 CPUs with $2.30 \mathrm{GHz}$. Even though the number of equations and number of event iterations only increase slightly from S2 to S3, the CPU time rises by factor 7.2.

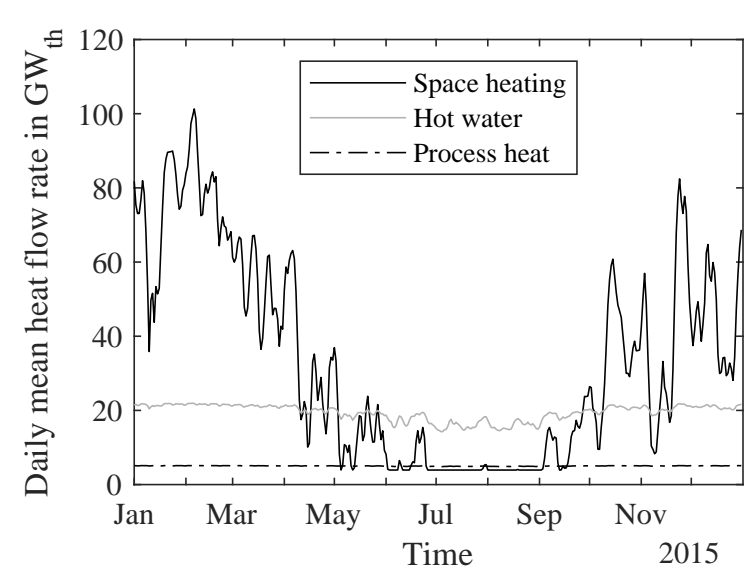

Figure 3. Heat demand curves of the different applications (daily mean values).

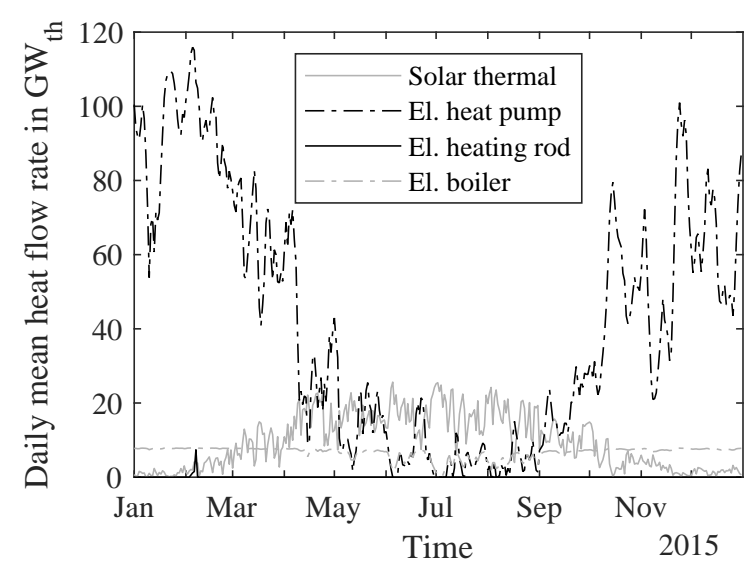

Figure 4. Heat supply curves of the different heat producers (daily mean values).

\section{Results}

\subsection{Design Results without Excess Power Uti- lization (S1)}

For the heating system, the design process returned a nominal power of the electric boiler of $10.62 \mathrm{GW}_{\text {th }}$, a solar thermal collector area of $200.6 \cdot 10^{6} \mathrm{~m}^{2}$ and a hot water storage volume of $15.04 \cdot 10^{6} \mathrm{~m}^{3}$ which leads to a specific solar heat production of $423.8 \mathrm{kWh} / \mathrm{m}^{2}$. In Figures 3 and 4 , the heat demand and heat supply curves are shown. The electric heating rod is used only from February 3rd to 7 th because then low ambient temperatures are reached.

The best configuration that was found by the optimizer in MATLAB is where a pumped hydro storage $\left(187.6 \mathrm{TJ}, 8.60 \mathrm{GW}_{\mathrm{el}}\right)$ and a lithium-ion battery $(284.3 \mathrm{TJ}$, $54.58 \mathrm{GW}_{\mathrm{el}}$ ) are charged in this order and Power-to-Gas in combination with combined cycle gas turbines is used. The remaining power is curtailed. The results are listed in Table 4. 
Table 4. Results of the different systems.

\begin{tabular}{|c|c|c|c|}
\hline & S1 & $\mathrm{S} 2$ & S3 \\
\hline $\begin{array}{l}\text { Renewable electric } \\
\text { power in } \mathrm{GW}_{\mathrm{el}}\end{array}$ & 513.7 & 510.5 & 505.4 \\
\hline $\begin{array}{l}\text { Electrolyzer power in } \\
\mathrm{GW}_{\mathrm{el}}\end{array}$ & 136.5 & 135.3 & 135.2 \\
\hline $\begin{array}{l}\text { Gas-to-Power power in } \\
\mathrm{GW}_{\mathrm{el}}\end{array}$ & 120.4 & 119.8 & 119.8 \\
\hline Gas storage in $10^{6} \mathrm{~kg}$ & 4315 & 4285 & 4315 \\
\hline $\begin{array}{l}\text { Maximum curtailed } \\
\text { power in } \mathrm{GW}_{\mathrm{el}} \\
\text { Curtailed energy in }\end{array}$ & 152.3 & 152.3 & 121.0 \\
\hline $\begin{array}{l}\mathrm{TWh}_{\mathrm{el}} \\
\text { Electricity consumption } \\
\text { of the heating system in } \\
\mathrm{TWh}_{\mathrm{el}}\end{array}$ & 30.51 & 28.76 & 12.61 \\
\hline - Electric heat pump & 119.87 & 120.18 & 117.05 \\
\hline - Electric heating rod & 0.25 & 0.27 & 17.99 \\
\hline - Electric boiler & 59.24 & 58.69 & 55.13 \\
\hline $\begin{array}{l}\text { Seasonal performance } \\
\text { factor of the heating } \\
\text { system }\end{array}$ & 2.804 & 2.807 & 2.644 \\
\hline $\begin{array}{l}\text { Solar thermal generation } \\
\text { in } \mathrm{TWh}_{\text {th }}\end{array}$ & 85.00 & 84.79 & 82.70 \\
\hline Annuity in bil. $€$ & 111.03 & 110.67 & 110.37 \\
\hline
\end{tabular}

\subsection{Proof of Concept of Excess Power Utiliza- tion}

In Figure 5, curves from a winter day are shown to visualize the function of the system with excess power utilization in the electric heat pump and the electric heating rod (S3). Over the day, only low solar thermal generation occurs and the electric heat pump supplies most of the heat demand. At 05:45 AM, excess power is available and completely utilized by the electric heat pump whereas from 11:30 AM the residual load cannot be consumed completely because the storage top temperature has reached the supply temperature of the electric heat pump and the electric heating rod is at maximum capacity which results in a noticeable temperature increase in the middle of the storage.

In Figure 6, a summer day with a significant solar heat production is shown. Because of the high temperatures in the storage due to previous sunny days, the excess power is only partly used and the rest is curtailed: In the beginning (8:00 AM), it is used in the electric heat pump and from 8:25 AM on in the electric heating rod because the temperature is too high for the heat pump. The short minimum in the available excess power at 11:30 AM results from a charging process in the lithium-ion battery.

\subsection{Results with Excess Power Utilization (S2 and S3)}

When excess power is used in the electric heat pump (S2), the system becomes more efficient; see Table 4 . The electric heat pump consumes just slightly more electric energy $\left(0.31 \mathrm{TWh}_{\mathrm{el}}\right.$, i.e. $\left.0.26 \%\right)$ but this small shift in the demand leads to a noticeable decrease in required renewable electric power $\left(-3.23 \mathrm{GW}_{\mathrm{el}}\right)$ as well as the Power-to-Gas, Gas-to-Power and gas storage units and thus a cost decrease of $0.33 \%$. Because the electric heat pump slightly increases the average temperature at the top of the storage, the electric boiler produces less heat which results in a small increase in the seasonal performance factor of the whole heating system from 2.804 to 2.807 but the solar thermal generation also drops by $0.25 \%$.

The decrease in the gas-related component sizes and cost continues when excess power is also used in the electric heating rod in the hot water storage (S3). In this case, the electric heat pump consumes less electric energy because the heat from the electric heating rod partly replaces heat which would otherwise have been produced by the electric heat pump. This results in a strong decrease in the seasonal performance factor to 2.644 as well as the solar thermal generation by $2.70 \%$ compared to $\mathrm{S} 1$.

The maximum curtailed power and energy both sink significantly by $20.58 \%$ and $58.65 \%$, respectively, compared to the reference case (S1), which leads to the observed increase in system efficiency and decrease in cost by $0.60 \%$. Of course, this value depends highly on the cost assumptions for the components but there can be no case in which the cost would rise because, due to the excess power utilization, only certain component sizes decrease but none increase significantly.

\section{Conclusion}

The existing models from Bode and Schmitz (2018) are extended, adding curtailment and more detail in the heating system. The combination of quasi-stationary MATLAB models and dynamic Modelica models allows for a good balance of speed and accuracy to investigate the influence of excess power utilization in electric heat pumps and electric heating rods. The reusability of the Modelica models enables the user to quickly build complex energy system models for dynamic simulation.

Starting at a cost-optimal point (S1), excess power usage in the electric heat pump (S2) and additionally in the electric heating rod (S3) is implemented. The results show that the cost can be reduced from $\mathrm{S} 1$ to $\mathrm{S} 2$ by $0.33 \%$ and from $\mathrm{S} 1$ to $\mathrm{S} 3$ by $0.60 \%$. Those are small values but only the control structure of the heating system has to be changed to enable the system to move the heat generation to times of high renewable energy generation. This way, the system becomes more cost and energy efficient. 

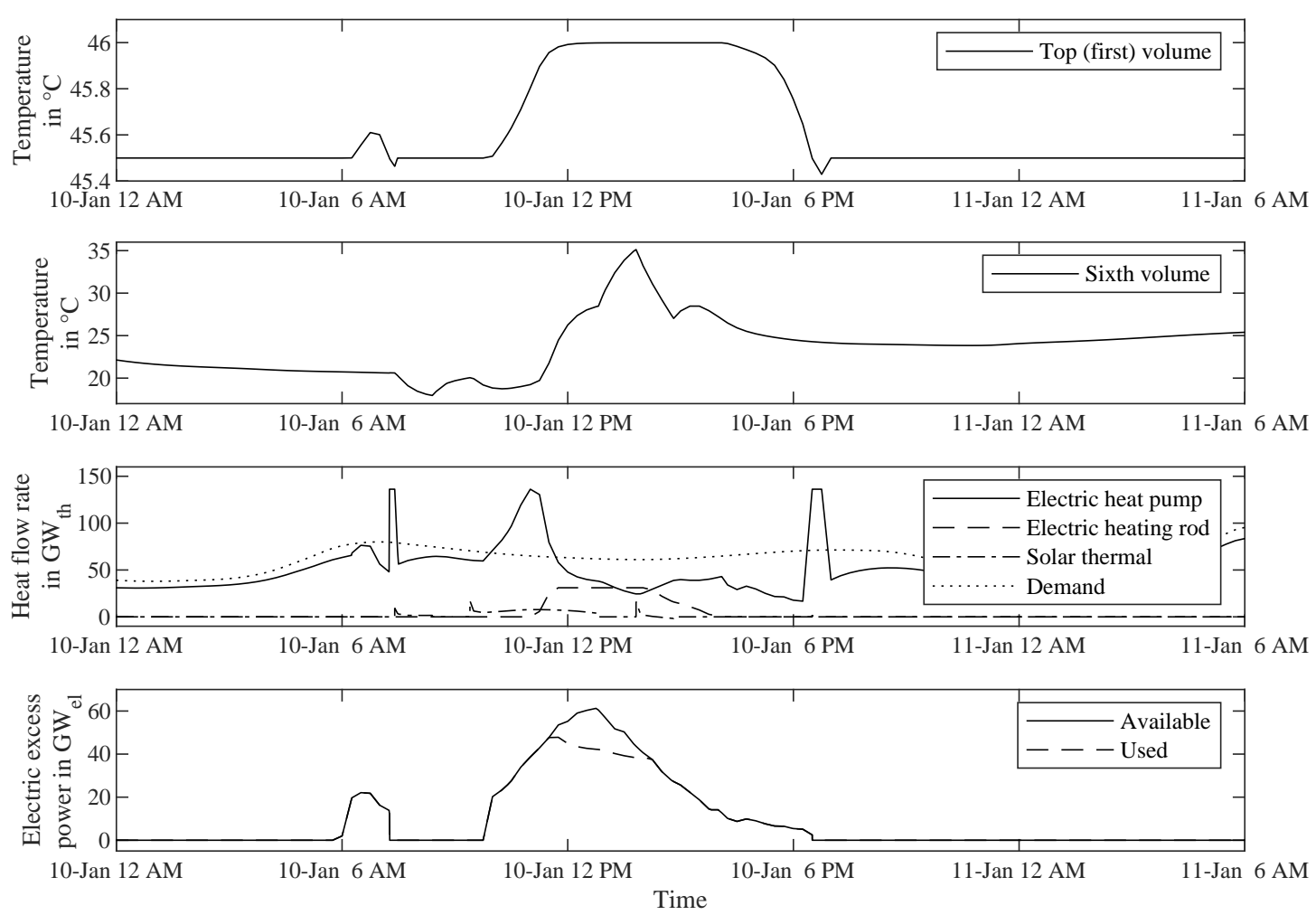

Figure 5. Curves of storage temperatures, heat flow rates and electric excess power in the heating system on a winter day in S3.
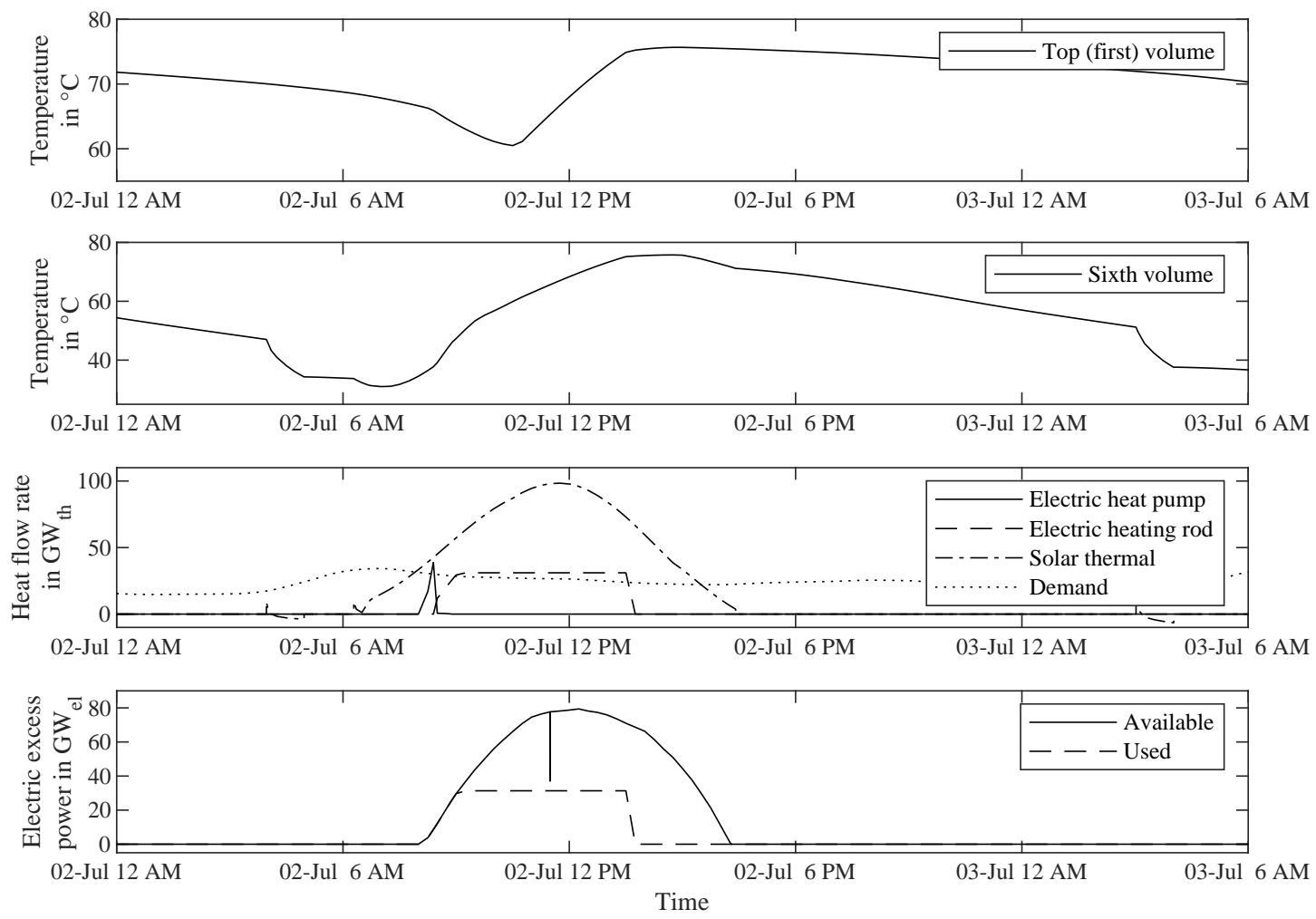

Figure 6. Curves of storage temperatures, heat flow rates and electric excess power in the heating system on a summer day in S3. 


\section{Acknowledgements}

The authors greatly acknowledge the funding from the German Federal Ministry of Economic Affairs and Energy for the project "ResiliEntEE - Resilienz gekoppelter Energienetze mit hohem Anteil Erneuerbarer Energien" (ResilientEE - Resilience of integrated energy networks with a high share of renewable energies, project number: 03ET4048).

\section{References}

Lisa Andresen, Pascal Dubucq, Ricardo Peniche, Günter Ackermann, Alfons Kather, and Gerhard Schmitz. Status of the TransiEnt Library: Transient simulation of coupled energy networks with high share of renewable energy. In Proceedings of the 11th International Modelica Conference, pages 695-705, Versailles, 2015. doi:10.3384/ecp15118695.

BDEW, VKU, and GEODE. BDEW / VKU / GEODE- Leitfaden. Abwicklung von Standardlastprofilen Gas. Technical report, Berlin, 2016.

Rosemarie Benndorf, Maja Bernicke, Andreas Bertram, Wolfgang Butz, Folke Dettling, Johannes Drotleff, Corinna Elsner, Eric Fee, Christopher Gabler, Christine Galander, Yvonne Hargita, Reinhard Herbener, Tim Hermann, Fabian Jäger, Judith Kanthak, Hermann Kessler, Yvonne Koch, David Kuntze, Martin Lambrecht, Christian Lehmann, Harry Lehmann, Sandra Leuthold, Benjamin Lünenbürger, Insa Lütkehus, Kerstin Martens, Felix Müller, Klaus Müschen, Diana Nissler, Sebastian Plickert, Katja Purr, Almut Reichart, Jens Reichel, Hanno Salecker, Sven Schneider, Jens Schuberth, Dietrich Schulz, Marlene Sieck, Ulla Strenge, Bärbel Westermann, Kathrin Werner, Christine Winde, Dietmar Wunderlich, and Brigitte Zietlow. Treibhausgasneutrales Deutschland im Jahr 2050 (Climate Change 07/2014). Technical report, Dessau-Roßlau, 2014.

Carsten Bode and Gerhard Schmitz. Dynamic Simulation and Comparison of Different Configurations for a Coupled Energy System with $100 \%$ Renewables. Energy Procedia, 155:412-430, 2018.

Johannes Brunnemann, Friedrich Gottelt, Kai Wellner, Ala Renz, André Thüring, Volker Roeder, Christoph Hasenbein, Christian Schulze, Gerhard Schmitz, and Jörg Eiden. Status of ClaRaCCS : Modelling and Simulation of Coal-Fired Power Plants with CO2 Capture. In Proceedings of the 9th International Modelica Conference, pages 609-618, Munich, 2012. doi:10.3384/ecp12076609.

Dassault Systèmes. Dymola 2019 - Dynamic Modeling Laboratory, 2018. URL https://www.3ds.com/ products-services/catia/products/dymola/.

DIN Deutsches Institut für Normung e.V. DIN EN 12831 Beiblatt 1:2008-07, Heizsysteme in Gebäuden - Verfahren zur Berechnung der Norm-Heizlast - Nationaler Anhang NA, 2008 .

Peter Elsner, Manfred Fischedick, Dirk Uwe Sauer, Berit Erlach, and Benedikt Lunz. Flexibilitätskonzepte für die Stromversorgung 2050. Technologien - Szenarien - Systemzusammen- hänge (Analyse aus der Schriftenreihe Energiesysteme der Zukunft). Technical report, München, 2015.

Norman Gerhardt, Fabian Sandau, Angela Scholz, Henning Hahn, Patrick Schumacher, Christina Sager, Fabian Bergk, Claudia Kämper, Wolfram Knörr, Jan Kräck, Udo Lambrecht, Oliver Antoni, Johannes Hilpert, Katharina Merkel, and Thorsten Müller. Interaktion EE-Strom, Wärme und Verkehr. Technical report, Kassel, Heidelberg, Würzburg, 2015.

Hamburg University of Technology. TransiEnt Library, 2018. URL https: //www.tuhh.de/transient-ee/en/.

Hamburg University of Technology, TLK-Thermo GmbH, and XRG Simulation GmbH. ClaRa 1.3.0, 2018. URL https: //claralib.com/.

Hans-Martin Henning and Andreas Palzer. Was kostet die Energiewende? Wege zur Transformation des deutschen Energiesystems bis 2050. Technical report, Freiburg, 2015.

IKM. Initiativkreis Europäische Metropolregionen in Deutschland, 2018. URL http://www. deutsche-metropolregionen.org/.

International Energy Agency. World Energy Outlook 2016. Technical report, Paris, 2016.

MathWorks. MATLAB 2018b, 2018a. URL https : //www . mathworks.com/products/matlab.html.

MathWorks. MATLAB Optimization Toolbox 8.1, $2018 \mathrm{~b}$. URL https://www.mathworks.com/products / optimization.html.

Modelica Association. Modelica and the Modelica Association, 2018. URL https://www.modelica.org/.

Joachim Nitsch, Thomas Pregger, Tobias Naegler, Dominik Heide, Diego Luca de Tena, Franz Trieb, Yvonne Scholz, Norman Gerhardt, Michael Sterner, Tobias Trost, Amany von Oehsen, Rainer Schwinn, Carsten Pape, Henning Hahn, and Bernd Wenzel. Langfristszenarien und Strategien für den Ausbau der Erneuerbaren Energien in Deutschland bei Berücksichtigung der Entwicklung in Europa und global. Schlussbericht. Technical report, Stuttgart, Kassel, Teltow, 2012.

Carsten Pape, Norman Gerhardt, Philipp Härtel, Angela Scholz, Rainer Schwinn, Tim Drees, Andreas Maaz, Jens Sprey, Christopher Breuer, Albert Moser, Frank Sailer, Simon Reuter, and Thorsten Müller. Roadmap Speicher. Speicherbedarf für erneuerbare Energien - Speicheralternativen - Speicheranreiz - Überwindung rechtlicher Hemmnisse. Endbericht. Technical report, Kassel, Aachen, Würzburg, 2014.

Hermann Recknagel, Otto Ginsberg, Kurt Gehrenbeck, Eberhard Sprenger, Winfried Hönmann, Ernst-Rudolf Schramek, and Karl-Josef Albers (editors). Taschenbuch für Heizung und Klimatechnik. DIV Deutscher Industrieverlag GmbH, München, 78th edition, 2017.

Frank Späte and Heinz Ladener. Solaranlagen. Handbuch der thermischen Solarenergienutzung. ökobuch Verlag, Staufen bei Freiburg, 11th edition, 2011. 
Sven Teske, Steve Sawyer, Oliver Schäfer, Thomas Pregger, Sonja Simon, Tobias Naegler, Stephan Schmid, Doruk Özdemir, Johannes Pagenkopf, Florian Kleiner, Jay Rutovitz, Elsa Dominish, Jenni Downes, Thomas Ackermann, Tom Brown, Simon Boxer, Ricardo Baitelo, and Larissa A. Rodrigues. energy [R]evolution. A Sustainable World Energy Outlook 2015. Technical report, Amsterdam, Brussels, 2015.

TLK-Thermo GmbH and Institut für Thermodynamik, Technische Universität Braunschweig. TILMedia 1.3.0 ClaRa, 2018. URL https://www.tlk-thermo. com/index.php/en/software-products / tilmedia-suite.

United Nations. Paris Agreement, 2015. 
Influence of Excess Power Utilization in Power-to-Heat Units on an Integrated Energy System with $100 \%$ Renewables 